\title{
LA DESARTICULACIÓN DE LA POLÍTICA ARGENTINA DE TURISMO SOCIAL EN MEDIADOS DEL SIGLO XX
}

\author{
Erica Schenke|*
}

Resumen

El Primer Peronismo (1943-1955) cristalizó el turismo social en la agenda pública argentina como medida distributiva, tendiente a disminuir la inequidad en el acceso al ocio. Como un caso inédito en América, el Estado se convirtió en el principal promotor y articulador del turismo social. El golpe de Estado de 1955 interrumpió todas estas iniciativas, dando inicio a una reconversión de la cuestión como política pública. Más allá de las sucesivas alternancias de gobierno que circunscribieron este más de medio siglo, el periodo presenta una línea de continuidad centrada en el declive de la política de turismo social, para nunca repetir el desarrollo alcanzado en los años cincuenta. Desde el enfoque del análisis de políticas, la investigación analiza este último periodo que sienta las bases del sistema actual de turismo social argentino, abordando el mismo como parte de un proceso histórico.

Palabras Clave: Política turística. Turismo. Turismo social. Peronismo. Argentina.

\section{THE DISARTICULATION OF THE ARGENTINIAN POLITICS OF SOCIAL TOURISM IN THE MIDDLE OF XX CENTURY}

\begin{abstract}
The First Peronism (1943-1955) incorporated social tourism into the argentine public agenda as a distributive policy, aimed at reducing inequity in access to leisure. As an unprecedented case in America, the State was the main promoter and articulator of social tourism. The coup d'état of 1955 interrupted all these initiatives, initiating a reconversion of the policy of social tourism. Beyond the successive alternations of government that have circumscribed this more than half a century, the period presents a line of continuity centered in the decline of the politics of social tourism, to never repeat the development reached in the fifties. From the perspective of policy analysis, the research analyzes this last period that gives rise to the foundations of the current system of social tourism, addressing it as part of a historical process.
\end{abstract}

Keywords: Tourism policy. Tourism. Social tourism. Peronism. Argentina.

\section{A DESARTICULAÇÃO DA POLÍTICA ARGENTINA DE TURISMO SOCIAL EM MEADOS DO SÉCULO XX}

O primeiro peronismo (1943-1955) cristalizou o turismo social na agenda pública argentina como uma medida distributiva, tendendo a reduzir a desigualdade no acesso ao lazer. Como um caso sem precedentes na América, o Estado tornou-se o principal promotor e articulador do turismo social. 0 golpe de estado de 1955 interrompeu todas essas iniciativas, dando origem a uma reconversão da questão como política pública. Além das sucessivas alternâncias de governo que circunscrevem isso há mais de meio século, o período apresenta uma linha de continuidade centrada no declínio da política de turismo social, para nunca mais repetir o desenvolvimento alcançado nos anos cinquenta. Do ponto de vista da análise de políticas, a pesquisa analisa este último período que estabelece as bases do atual sistema de turismo social argentino, abordando-o como parte de um processo histórico.

Palavras Chave: Política turística. Turismo. Turismo social. Peronismo. Argentina.

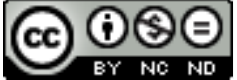

Licenciada por Creative Commons Atribuição Não Comercial / Sem Derivações/ 4.0 / Internacional

\footnotetext{
* Posdoctora en Ciencias Humanas por la Universidad de Buenos Aires (2017). Doctora en Ciencias Políticas y Administración Pública, por la Universidad Nacional de Cuyo (2015). Licenciada en Turismo, por la Universidad Nacional del Sur (2010). Docente-investigadora en el Departamento de Geografía de la Universidad Nacional del Sur (Argentina) y miembro del Consejo Nacional de Investigaciones Científicas y Técnicas (CONICET/ Argentina). Sus temás de investigación son el análisis del turismo en sus aspectos políticos y socio-económicos. En estas áreas cuenta con la publicación de diferentes libros, capitulos de libros y articulos en revistas científicas nacionales e internacionales de la especialidad. [erica.schenkel@uns.edu.ar].
} 


\section{INTRODUCCIÓN}

Los primeros antecedentes vinculados al turismo social en Argentina se iniciaron principalmente en la década de 1930 y como en materia turística en general, surgieron a partir de actores privados. Organizaciones cristinas y laicas, empresas ferroviarias y sindicatos, reprodujeron las primeras acciones que se estaban desarrollado en Europa, con el objetivo de fomentar las prácticas recreativas y turísticas en sus afiliados, empleados y seguidores. Estas acciones aisladas constituyeron los antecedentes de la ambiciosa política de turismo social peronista que permitió que este tipo de prácticas se extendieran al conjunto del territorio nacional, alcanzando a sectores sociales antes excluidos (SCARZANELLA, 1998).

Con la llegada de Perón al poder, el Estado Nacional asumió por primera vez una función de promotor en el área, impulsando una serie de acciones tendientes a facilitar el acceso de los trabajadores al turismo y otras medidas estructurales que, si bien no surgieron dentro de la arena turística, fueron determinantes al proveer tiempo disponible y recursos financieros (PASTORIZA; TORRE, 1999).

La retórica peronista en la arena del ocio y el turismo, fue acompañada de concreciones sociales, que significaron la movilización de los trabajadores y conciencia de clase. La afectación de recursos económicos, la sanción de normativa específica, el despliegue de infraestructura estatal, la consideración otorgada en los medios de difusión gubernamental y la valoración social de una cuestión hasta entonces subalterna, reflejan la irrupción del turismo social en la agenda pública argentina.

El golpe de Estado de 1955 interrumpió todas aquellas iniciativas identificadas con el partido justicialista, iniciando un periodo de bloqueo y reconversión del turismo social en la agenda gubernamental, asociado a la secuencia de gobiernos democráticos y dictatoriales. A partir de la invalidación de normas, la transferencia de recursos a provincias, sindicatos y privados y la amputación de derechos sociales, se desarticuló progresivamente el sistema estatal de turismo social, para nunca volver a alcanzar el desarrollo de los años 1950. Si bien el regreso de la democracia significó la inserción definitiva del turismo social en la agenda pública, una serie de elementos estructurales hacen que ocupe una posición subsidiaria entre las políticas del sector.

La investigación que se presenta a continuación analiza la política de turismo social en este último periodo. A diferencia de lo que sucede con el estudio de la política en el Primer Peronismo, exite un vacio relativo de este tipo de abordajes desde 1955 (PASTORIZA, 2002). Particularmente, la investigación busca explicar el proceso mediante el cual se logró desarticular aquella política que alcanzó el mayor desarrollo en América (incluyendo, incluso, la disposición de complejos vacacionales estatales en diferentes provincias del país), así como su reformulación a partir de nuevos factores constitutivos.

Más allá de las sucesivas alternancias de gobierno que circunscribieron este más de medio siglo, el periodo presenta una línea de continuidad centrada en el declive de la política de turismo social, para nunca repetir el desarrollo alcanzado en los años cincuenta. El periodo se estructura en dos etapas: (1) etapa de alta inestabilidad (1955-1983), en la cual el turismo social adquiere una posición itinerante en la agenda gubernamental, asociada a la alternancia entre dictaduras y gobiernos democráticos; (2) etapa de reconversión (1983-2015), a partir del regreso de la democracia, que implica una reformulación del turismo social como asunto público, pasando a ocupar una posición subsidiaria entre las políticas del área.

Entendiendo tal política como un proceso social, el estudio refleja el valor analítico de contemplar los factores extrínsecos que le confieren sentido y contenido político. El análisis permite identificar aquellos elementos que sientan las bases del actual sistema de turismo social argentino, abordando el mismo como parte de un proceso histórico.

Este texto, se organiza, a seguir en cuatro apartados. El primero de ellos aborda la cuestión de la política de turismo social, en tanto política pública, como objeto de estudio. Luego se presenta el apartado metodológico, para dar lugar a continuación a los resultados y discusión, que articulan la irrupción del turismo social en la agenda de gobierno con su reformulación en la etapa post-peronista. Finalmente, se presenta el apartado de las reflexiones finales.

\section{LA POLÍTICA PÚBLICA DE TURISMO SOCIAL COMO OBJETO DE INVESTIGACIÓN}

La multiplicidad de ciencias que abordan su estudio dificulta un consenso en torno a qué se considera política pública. No obstante, si se analizan las principales concepciones, se destacan elementos coincidentes que permiten caracterizar la esencia de las mismas (GONZÁLEZ, 2004; VALENCIA \& ÁLVAREZ, 2008; PÉREZ SÁNCHEZ, 2006).

Pérez Sánchez (2006) señala el componente institucional, por emanar de una autoridad formal legalmente constituida; el decisorio, por entrañar un proceso decisional; el comportamental, por implicar la acción o inacción acerca una cuestión determinada; y el causal, por constituir productos con efectos en la sociedad. Desde una misma perspectiva, Valencia \& 
Álvarez (2008) refieren a tres elementos clave: el Estado, por ser parte de sus competencias ineludibles y por tanto emanar principalmente de éste; la acción, al trascender la simple intención para convertirse en un acto concreto; y la intervención, por implicar una actuación en la sociedad para transformar un estado de cosas. Por tanto, mientras que la política (politics), alude al poder, su distribución y su lucha por obtenerlo, la política (policy), refiere a una acción pública específica. Si bien ambas concepciones comparten un mismo vocablo, refieren a diferentes temáticas vinculadas (LOSADA, 2003; GONZÁLEZ, 2004; FRANCO \& LANZARO, 2006, SUREL, 2006).

La relación entre ambas categorías es parte de una discusión histórica centrada en la dependencia de una sobre otra: las políticas como productos de la política, o las políticas como determinantes de la política. Superando ambas perspectivas, la ciencia política contemporánea parte de una comprensión compleja, reconoce cierta autonomía de las políticas en cuanto a la estructura de poder inicial y a su vez destaca su capacidad para modificarla. Existe una dependencia mutua: las políticas públicas son autónomas pero enmarcadas en la arena en la que convergen y luchan las fuerzas políticas (PÉREZ SÁNCHEZ, 2006).

En cuanto a la clasificación, entre las diversas tipologías planteadas, se destaca la tradicional de Lowi (1964), que parte de los impactos de costes y beneficios que los distintos grupos de interés esperan de una política: regulatorias o reglamentarias, distributivas y redistributivas; posteriormente, al considerar la coacción como otro importante elemento de distinción, el autor agrega una nueva categoría, las constitutivas (LOWI, 1972). Las regulatorias 0 reglamentarias, fijan reglas de comportamiento principalmente mediante legislación; las redistributivas, se llevan a cabo mediante instrumentos fiscales canalizados en programas de asistencia, clasificando a las personas como destinatarios o no de las ventajas asociadas; las distributivas tienden a garantizar la igualdad de acceso a los recursos; y las políticas constitutivas, definen las reglas sobre reglas.

Subirats (2010), que parte de la primera clasificación de Lowi (1964), define las tipologías de acuerdo a los costes y beneficios. Afirma que las políticas regulativas, presentan costes concentrados y beneficios difusos; las políticas redistributivas, costes concentrados y beneficios concentrados; $y$ las políticas distributivas, costes difusos y beneficios concentrados.

El autor afirma que los gestores de la política prefieren la implementación de políticas distributivas, debido a que no suelen existir resistencias manifiestas a la medida y reciben en cambio el agradecimiento directo de aquellos beneficiados con el servicio o la infraestructura provista. La política de turismo social, objeto de investigación de esta investigación, se ajusta a esta última tipología, tendiente a garantizar la igualdad de acceso a los recursos turísticos.

La política de turismo social constituye la respuesta gubernamental a obstáculos particulares, de índole diversa, que impiden el disfrute de las prácticas turísticas por el conjunto de la sociedad (SCHENKEL, 2017). Estas barreras de acceso, que determinan los colectivos a beneficiar y las acciones a implementar, no son universales, sino que responden a un tiempo y a un espacio determinado. Las variables económicas y sociales, así como las bases históricas e ideológicas, condicionan el tipo de política a aplicar (MUÑIZ, 2001; CAZES, 2002).

Las primeras acciones estatales vinculadas al turismo social se impulsaron en países de regímenes socialistas 0 de economías planificadas, a medida que se fueron logrando los derechos laborales. Los Estados de gobiernos liberales las adoptaron posteriormente, en especial al finalizar la Segunda Guerra Mundial. La proclamación del derecho a las vacaciones había significado la disponibilidad de tiempo libre en sectores sociales mayoritarios, pero esta conquista laboral no implicó su inclusión efectiva en las prácticas turísticas, debido a imposibilidades económicas y a la inexperiencia como turistas (BITS, 1972; HUGHES, 1991; KINDERIS, 2010; VILELA, 2011; LÓPEZ, 2016).

Europa fue el epicentro de estas primeras iniciativas: Estados con mandatos autoritarios y democráticos incorporaron al turismo como una necesidad social en el marco de las políticas de bienestar. En la Italia fascista se promovieron vacaciones para los trabajadores con fines de instrucción, impulsadas por la Opera Nazionale Dopolavoro; y en la Alemania nazi, se impulsaron propuestas de turismo social tendientes a imbuir de nacionalismo a la población, mediante el Kraft durch Freude. En Francia, con las políticas de ocio del Frente Popular, se crea un Ministerio específico, el Ministère des Loisirs; en Bélgica, se impulsa un organismo promotor de turismo social, que promueve la creación de centros de vacaciones, asociaciones y organismos específicos; en Suiza, se lanza la caja de ahorros para los viajes de veraneo; y en España y Portugal, se impulsan subvenciones destinadas a las asociaciones vinculadas al turismo y la recreación, a través de la Obra Sindical de Educación y Descanso y el Frente Nacional para la Alegría no Trabalho, respectivamente (COMISIÓN EUROPEA, 2006). 


\section{METODOLOGÍA}

La investigación presenta un estudio de tipo explicativo, de carácter historiográfico, que analiza la evolución de la política de turismo social a lo largo del último siglo, asociada a las distintas funciones que asumió el gobierno en la materia, la inestabilidad del sistema político, las recurrentes crisis económicas y las transformaciones en los patrones que condicionan la toma de decisiones. Este análisis permite explicar cómo el turismo social que supo ocupar una posición preponderante en la problematización de la cuestión turística, contemporánea a la institucionalización del área y al impulso de los instrumentos que sentaron las bases para el desarrollo del sistema turístico argentino a mitad de siglo XX, termina ocupando una posición subsidiaria entre las políticas del sector, transfiriendo parte de los recursos afectados a la promoción de los arribos internacionales.

La investigación parte del enfoque de análisis de políticas, particularmente de los estudios amplios de evaluación, que alejados de criterios deterministas, permiten explicar la acción pública en el área a partir de abordajes holísticos y contextualizados (PÉREZ SÁNCHEZ, 2006). Desde esta perspectiva, la política pública constituye "la respuesta del sistema políticoadministrativo a una situación de la realidad social juzgada politicamente como inaceptable" (SUBIRATS, 2010:1). El proceso se inicia con la toma de conciencia ante ciertos síntomas del entorno e incluye cada una de las decisiones 0 acciones correspondientes a la acción pública, tanto reglas formales (leyes, decretos, órdenes, etc.), como actos individuales (decisiones administrativas, autorizaciones, subvenciones, etc.).

Entre las técnicas de investigación, se destaca el análisis de documentos de tipo: normativos, Constituciones, Leyes, Decretos, Decisiones Administrativas y Resoluciones; estadísticos, Registro Anual Día/Turista de los Programas de Turismo Social; manifestaciones oficiales, Presupuestos Nacionales, Cuentas de Inversión, Memorias Detalladas del estado de la Nación, Cartas de Compromiso, Planes Estratégicos de Turismo Sustentable, discursos, escritos y prensa pública; y programas y planes específicos, difusión oficial e informes.

La investigación documental se complementa con técnicas de observación participante en las tres áreas clave del sistema de turismo social argentino: la Dirección Nacional de Prestaciones Turísticas (Ciudad

\footnotetext{
${ }^{1}$ Perón participó en el golpe militar de 1943 comandado por el Grupo de Oficiales Unidos (GOU), que puso fin al gobierno conservador de Ramón Castillo. Luego de desempeñar diferentes cargos en el nuevo gobierno, destacándose como Secretario de Trabajo y Previsión, fuerza la convocatoria de elecciones democráticas, que lo llevarán a la presidencia en 1946. Este cargo
}

Autónoma de Buenos Aires), que centraliza la gestión de los Programas desde la década de 1990; y las Unidades Turísticas de Chapadmalal (provincia de Buenos Aires) y Embalse (provincia de Córdoba), complejos construidos por el primer Peronismo a mediados del siglo $X X$ y que hoy día continúan centralizando el sistema de turismo social argentino.

Las planillas de observación incluyeron el relevamiento de cada una de las plantas hoteleras, abiertas y clausuradas, que conforman los complejos (Embalse: hoteles $n^{\circ} 1$ al 7; Chapadmalal: hoteles $n^{\circ} 1$ al 9), como las áreas recreativas y comercios circundantes. Esto permitió analizar el estado general del equipamiento e instalaciones y la dinámica de los Programas de Turismo Social.

La visita a la Dirección en tanto, brindó información asociada a la operatoria del área, en aspectos vinculados al diseño, implementación y evaluación de la política, a partir de la interacción con personal de Dirección, Fiscalización, Consultoría y Programas.

Fialmente, se realizaron entrevistas a diferentes actores públicos y privados que ocuparon un lugar preponderante en el diseño e implementación de la política de turismo social en diferentes momentos históricos. A pesar de haber aportado información relevante para el estudio, la realización de entrevistas encontró cierta resistencia por parte de algunos actores, principalmente en concecionarios y hoteleros, a cargo de la prestación del servicio, y en ciertas autoridades gubernamentales, que seguían en funciones al momento del análisis.

\section{RESULTADOS Y DISCUSSIÓN}

\subsection{El origen de la política de turismo social en Argentina}

Contemporáneamente a las primeras iniciativas europeas, Perón reconoció en el tiempo libre y el ocio un área clave para la intervención del Estado y el desarrollo de políticas públicas ${ }^{1}$. Desde su llegada a la Secretaría de Trabajo y Previsión (1943) el turismo social formó parte de las reivindicaciones proclamadas en el discurso oficial. Como un caso inédito en América ${ }^{2}$, el Estado se convirtió en el principal promotor y articulador de este tipo de iniciativas, afectando por primera vez recursos públicos en el área

lo mantendrá hasta su derrocamiento en 1955 , con un nuevo golpe de Estado a manos de la "Revolución Libertadora".

2 La mayoría de los estados latinoamericanos promueven iniciativas vinculadas al turismo social recién a partir de 1970, a excepción de los países más retrasados en términos socio-económicos que aún no cuentan con propuestas de este tipo. 
en forma específica. La política estatal de turismo social adquirió una magnitud y visibilidad que no se repitió en ningún otro periodo de la historia argentina. La cuestión alcanzó una posición preponderante en el área turística, que perduró incluso hasta el último cuarto de siglo XX.

Hasta entonces, el interés gubernamental por la actividad turística se había limitado a un fundamento territorial, motivado por la necesidad de consolidar un Estado Nacional en incipiente desarrollo, con extensos territorios despoblados. La actividad turística se insertó así en la agenda pública argentina asociada a la política de protección ambiental, como aseguradora de la soberanía nacional. Con el origen de un proceso de industrialización con promoción social en la década del 1930, organizaciones cristinas y laicas, empresas ferroviarias y sindicatos, con influencia europea, comenzaron a imitar las primeras acciones de turismo social que se estaban desarrollado en el Viejo Continente, extendiendo colonias de vacaciones, centros recreacionales y alojamientos con el objetivo de fomentar las prácticas recreativas y turísticas en sus afiliados, empleados y seguidores. El Estado se limitó a acompañar estas iniciativas indirectamente, controlando y reglamentando actividades comerciales de ocio, extendiendo la red de carreteras, implementando políticas de equipamiento urbano y en casos puntuales, facilitando su desarrollo con financiación (SCARZANELLA, 1998).

Recién a parir del primer Peronismo estas acciones se regularizan y extienden al conjunto del territorio nacional, definiendo la inequidad en el acceso al ocio como problema público, asociado a uno de los tres pilares de gobierno, la justicia social. El primer Peronismo (1943-1955) consolidó el proceso iniciado en los años treinta, categorizado por los autores Torre \& Pastoriza (2002) como "democratización del bienestar", a partir del cual se transfirieron derechos básicos hacia los estratos populares y se promovió su ascenso social mediante la redistribución del ingreso nacional.
Este proceso de ampliación de derechos incluyó tanto a los que refieren a las necesidades más elementales, como la vivienda, la jubilación, la salud y la educación; como aquellos otros, considerados hasta el momento exclusivos de una minoría, entre los cuales se encontraban los vinculados al esparcimiento, como la asistencia a espectáculos deportivos y musicales, cines $y$, especialmente, el desarrollo de prácticas turísticas.

La iniciativa se incluyó dentro de las medidas reivindicatorias, asociada a las necesidades de jornada limitada, vacaciones pagadas y mejoras salariales. Perón planeaba "....levar un millón de trabajadores con sus familias a la montaña o al mar, alojarlos y darles de comer por un precio sumamente módico, que pueda representar el ahorro de unos pesos de su salario durante el año" (PERÓN, 9 de abril de 1945). Esta previsión, que en principio parece lejana, terminó estando bastante próxima al impacto de los programas: Pastoriza \& Torre (1999) señalan que en la temporada veraniega de principios de los ' 50 , los beneficiarios que habian arribado solamente a Mar del Plata alcanzaron el medio millón de visitantes.

En el $2^{\circ}$ Plan Quinquenal (ley 14184/54, XXX.E.1) el turismo formó parte de las exclusivas diez prioridades que se destacaron, previendo destinar al área m\$n 20.000 .000 (pesos moneda nacional veinte millones), cerca del $1,5 \%$ del presupuesto asignado a Acción Social. Los recursos presentaban afectación específica con el objetivo de emprender acciones de carácter redistributivo, que contribuyeran con los tres pilares de gobierno: justicia social, independencia económica y soberanía política (PRESIDENCIA DE LA NACIÓN, 1953). El gobierno peronista articuló una serie de acciones específicas tendientes a facilitar el acceso de los trabajadores al turismo y otras estructurales, que si bien no surgieron dentro de la arena turística, fueron determinantes al proveer tiempo de descanso y recursos financieros en los sectores sociales mayoritarios (Figura 1).

Figura 1. Origen y consolidación de la política de turismo social (1943-1955).

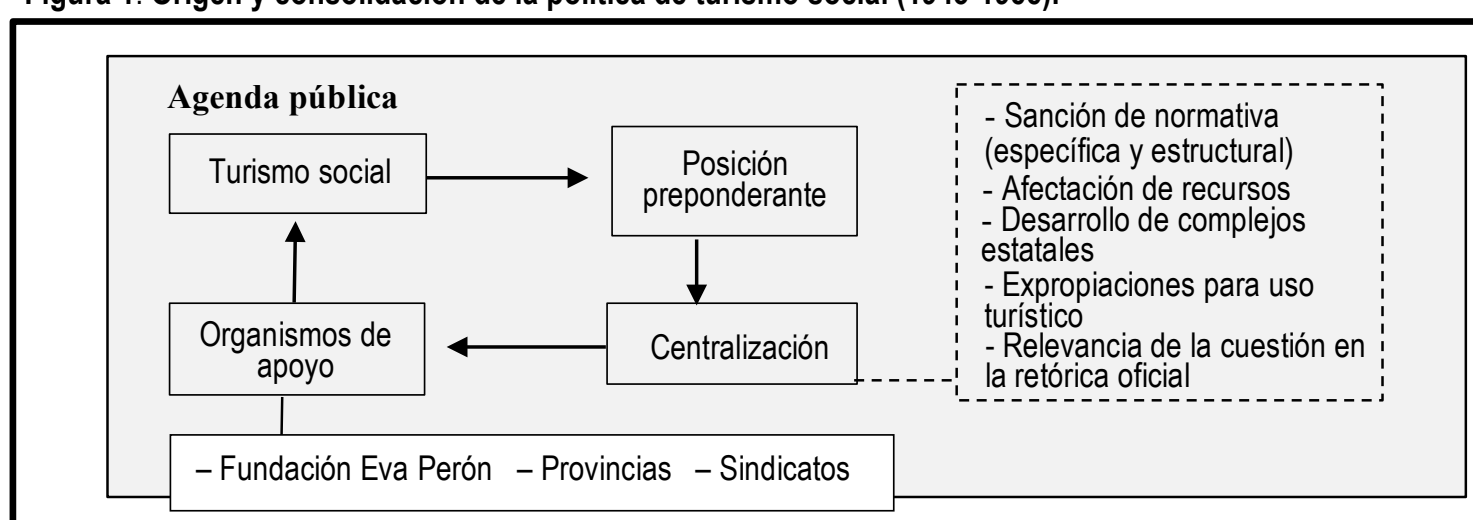

Fuente: Schenkel, 2017. 
Entre estas últimas, se destacan las medidas distributivas: salario básico, mínimo y vital, sueldo anual complementario, salario familiar, sistema de negociaciones colectivas, pleno empleo, días feriados pagos, pensiones a la vejez, indemnizaciones por despidos; que lograron mejorar considerablemente las condiciones socio-económicas de los sectores populares.

Las normativas vinculadas al descanso en tanto, permitieron la disponibilidad de tiempo libre en los trabajadores. Perón (1945, 9 de abril) afirmaba que: "cada hombre debe tener el necesario descanso diario para reponer sus fuerzas, el necesario descanso semanal para reponer su espíritu y el necesario descanso anual, para reponer las fuerzas del cuerpo y del alma".

Al descanso dominical y sabatino de medio día, se añadieron la jornada limitada de ocho horas diarias y las nuevas festividades que se incorporaron al calendario nacional, como el 1 y 6 de enero, el lunes y martes de carnaval, jueves y viernes de semana santa, el 1 y 25 de mayo, el 20 de junio, el 9 y 26 de julio, 12 y 17 de agosto, 11 y 21 de septiembre, 12 y 17 de octubre, 1 y 2 de noviembre, 8, 24 y 31 de diciembre y los feriados específicos para cada categoría profesional. Es dable destacar el decreto 1740/45, que extendió el derecho a las vacaciones anuales pagadas con goce de sueldo a todos los trabajadores y empleados argentinos en relación de dependencia.

A este conjunto de acciones se añadieron otras destacadas en materia turística, como la ampliación de infraestructura de comunicaciones entre las principales ciudades y destinos turísticos, la jerarquización del organismo público, los descuentos en las tarifas de transporte, el control estatal de precios en servicios de alojamiento, alimentación y esparcimiento, la organización de programas de turismo total 0 parcialmente subsidiados, la creación de colonias vacacionales y centros recreacionales, la asignación de recursos económicos especíicos para programas de turismo social y la compra, construcción y alquiler de hoteles para dar albergue.

También se promovió el desarrollo de alojamientos privados para uso turístico, a partir del Préstamo Nacional Hotelero y de la Ley de Propiedad Horizontal (1948), asociaciones sindicales y particulares pudieron construir hoteles e instalaciones turísticas 0 alquilar 0 adquirir sus propios departamentos en los principales destinos del país, respectivamente.

En este periodo el Estado pasó a administrar una extensa oferta hotelera, que incluía los alojamientos de las empresas británicas, con la nacionalización de los ferrocarriles, los establecimientos dependientes de la antigua repartición de Parques Nacionales y otros trasferidos por las provincias. También se efectuaron expropiaciones a particulares, hoteles, tierras, estancias y chalets en áreas de atractivo turístico, se pusieron a disposición del Estado para la promoción del turismo social.

A partir de esta estructura de alojamientos y con nuevos edificios construidos por el Ministerio de Obras Públicas, se puso en marcha un sistema estatal de colonias de vacaciones en los principales centros turísticos del país, destacándose las unidades turísticas de Ezeiza (Buenos Aires), Puente del Inca (Mendoza), Embalse (Córdoba) y Chapadmalal (Mar del Plata). Estas últimas constituyeron los principales complejos estatales para uso turístico y hoy en día continúan sosteniendo el sistema de turismo social argentino.

El Decreto-Ley 33302/45 referido al salario mínimo, básico y sueldo anual complementario, constituyó el emblema de la política de turismo social peronista. Tendiente a "elevar" el nivel de vida de las clases trabajadoras, incluyó al ocio activo entre las necesidades básicas, definiendo al salario vital mínimo como "la remuneración del trabajo que permite asegurar en cada zona, al empleado y obrero y a su familia, alimentación adecuada, vivienda higiénica, vestuario, educación de los hijos, asistencia sanitaria, transporte o movilidad, previsión, vacaciones y recreaciones" (Art. 18).

La norma determinaba que el $3 \%$ del aguinaldo, derivado de un aporte del $5 \%$ del sueldo anual complementario que debía depositar el empleador en el Instituto Nacional de Remuneraciones (pudiendo retener un $2 \%$ del pago al empleado), se destinaría al fomento del turismo social entre los obreros y sus familias, contribuyendo a diversas especificidades: atender gastos de colonias de vacaciones y lugares de descanso; facilitar las estadas y el disfrute de los beneficios, abaratando precios de trasporte y otros gastos relacionados y poniendo a disposición los medios necesarios; adquirir terrenos, compra, construcción, ampliación y refracción de edificios, como todo el mobiliario necesario para la puesta en funcionamiento; acordar subsidios y atender los servicios financieros de préstamos destinados a tal fin.

El Decreto-Ley permitió al Instituto Nacional de Remuneraciones ceder en arrendamiento a los sindicatos, que desempeñaron una función destacada en esta política peronista, la locación o administración de los establecimientos adquiridos por el Estado con fines turísticos. En una segunda etapa, con la Ley 13.992/50, las acciones de turismo social que reunía el Instituto se transfirieron a la Fundación Eva Perón (FEP), pasando a centralizar recursos, unidades 
turísticas y demás elementos específicos ${ }^{3}$. La norma determinó que el Fondo de Turismo Social, conformado a partir del $3 \%$ de la deducción establecida al aguinaldo, debía depositarse directamente a la flamante Fundación.

A partir de este andamiaje de medidas, la política de turismo social peronista logró incorporar a las prácticas turísticas a sectores sociales que históricamente habían estado privados de su disfrute (SCHENKEL, 2015).

Los módicos costos de las propuestas oficiales, que en muchos casos reunían el conjunto de los servicios turísticos totalmente subvencionados, así como la articulación con la Fundación Eva Perón, que permitió incluir a aquellos colectivos excluidos de la estructura gremial, posibilitó la participación de parte de los sectores obreros, marginados de estas prácticas por sus ingresos, que lograron acceder al turismo en muchos casos por primera vez.

Más allá de la retórica oficial, la afectación de recursos económicos, la sanción de normativa específica, el despliegue de infraestructura estatal, la consideración otorgada en los medios de difusión y la amplia valoración social de una cuestión hasta entonces marginal, reflejan la irrupción del turismo social en la agenda pública, constituyendo un momento paradigmático en la historia Argentina.

\subsection{La política de turismo social en el post- peronismo}

El golpe de Estado de 1955 interrumpió aquellas iniciativas identificadas con el partido justicialista, iniciando un periodo de bloqueo y reconversión del turismo social en la agenda gubernamental, que se asocia a la alta inestabilidad del sistema democrático. A partir de la invalidación de normas, la transferencia de recursos a provincias, sindicatos y privados y la amputación de derechos sociales, se desarticuló progresivamente el sistema estatal de turismo social, para nunca repetir el desarrollo alcanzado en los años 1950.

A partir del Decreto 11992/56, las Unidades Turísticas de Chapadmalal, Embalse y de Alta montaña, dependientes de la Fundación Eva Perón, quedaron transitoriamente bajo jurisdicción del Ministerio de Hacienda, con el propósito de "regularizar" la prestación de los servicios sociales, mediante "organismos administrativos competentes" que permitieran satisfacer las "finalidades para las cuales fueron creados".

A los escasos meses éstas se transfirieron a la Dirección General Inmobiliaria, buscando emprender una profunda reestructuración del "deficitario" sistema de explotación vigente; como así también aquellos bienes inmuebles, muebles, semovientes y de consumo, el personal afectado y cada uno de los elementos que integraban el departamento de turismo de la antigua Fundación (DECRETO 17.800/56).

Desde entonces el turismo social pasó por ciclos pendulares de bloqueo y activación en periodos de dictaduras y gobiernos democráticos, respectivamente, hasta la vuelta de la democracia en el año 1983 (Figura 2).

Figura 2. Desarticulación del sistema de turismo social peronista (1955-1983).

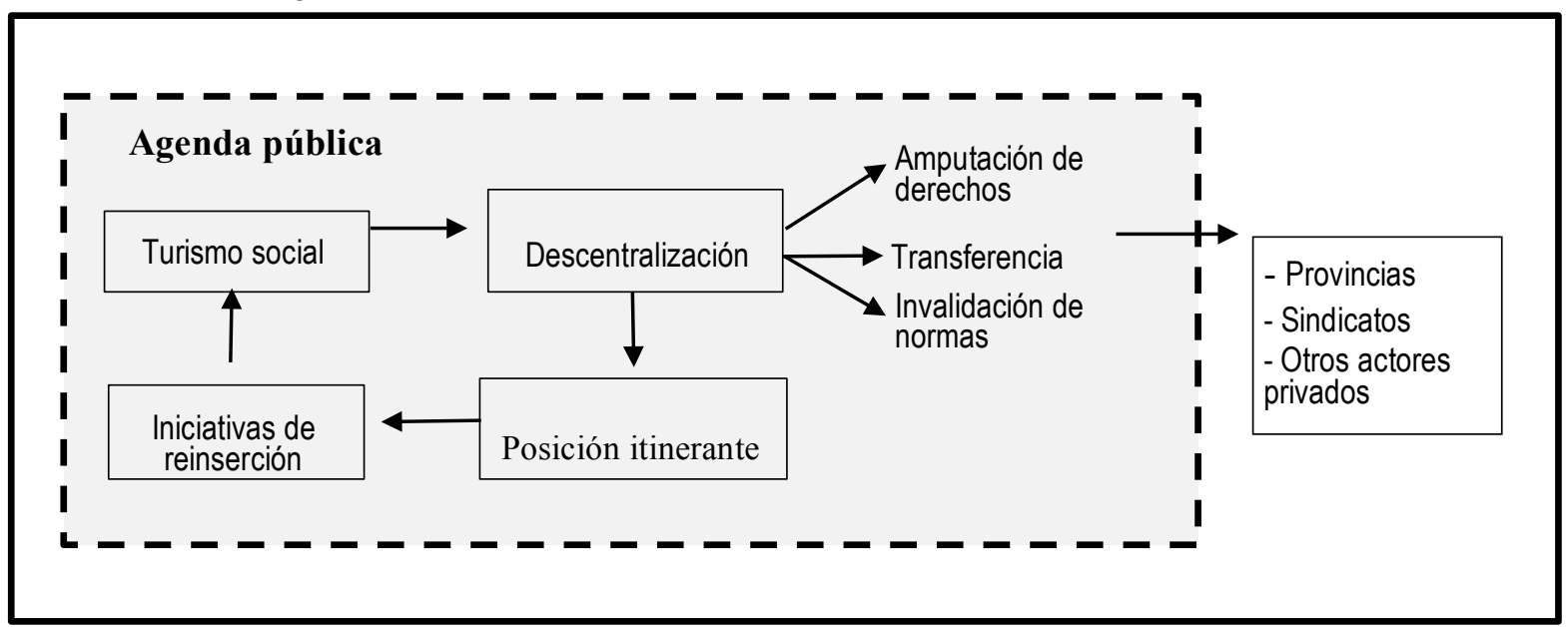

Fuente: Schenkel, 2017.

3 En el año 1948 se creó la Fundación de Ayuda Social María Eva
Duarte de Perón (Decreto N 20.564), dos años después Fundación
Eva Perón - FEP (Decreto N²0.258/50), una institución de ayuda social con financiación estatal y aportes de privados, que dirigía la Sra. Eva Duarte de Perón. 
Los distintos interregnos democráticos pretendieron reinsertar el turismo social en la agenda gubernamental, a partir del sistema de colonias de vacaciones que había instaurado el peronismo, especialmente con las Unidades Turísticas de Embalse y Chapadmalal, sin embargo, los recurrentes golpes de Estado coartaron estas iniciativas.

El presidente Arturo Frondizi creó un órgano específico, la Sección de Turismo Social, dentro de la Dirección Nacional de Turismo, tendiente a promover y organizar el turismo social para docentes, empleados, jubilados, pensionados, obreros, estudiantes y trabajadores independientes. La sanción de la primera Ley Nacional de Turismo (14574/58) y su decreto reglamentario (9468/61), destaca al "turismo educacional y social" entre las tipologías turísticas, tendiente a asegurar la valoración, estímulo y aprovechamiento de los recursos turísticos, poniendo éstos al servicio de la salud física y mental del pueblo y de la economía del país.

La Sección de Turismo Social centralizó diversas acciones específicas: promoción y gestión de créditos turísticos personales a pagar mensualmente con descuentos salariales; gestión de bajas tarifarias en servicios de transporte y hospedajes; formalización de vínculos con organizaciones gremiales para coordinar acciones asociadas; impulso de un "ahorro turístico familiar" para la realización de prácticas turísticas; organización de congresos de turismo social para favorecer su desarrollo; promoción de acuerdos con provincias y municipios para fortalecer estos flujos turísticos de manera permanente; fomento y apoyo de colonias de vacaciones, balnearios, campos deportivos y de recreación y demás establecimientos destinados al "turismo económico" en zonas de interés turístico; organización y realización de excursiones a bajo precio; y promoción del turismo social internacional (LEY 14574/58, Art. 14).

El nuevo golpe de Estado deja truncos todos esos proyectos. La autodenominada "Revolución Argentina" canceló la Sección de Turismo Social, transfiriendo las acciones vinculadas a la Secretaría de Promoción y Asistencia de la Comunidad dentro del Ministerio de Bienestar Social (Ley 17271/67), y derogó los artículos de la Ley Nacional de Turismo destinados a la promoción del turismo social (Ley 17618/68); para finalmente, interrumpir todos los programas oficiales, argumentando saldo deficitario y falta de eficiencia en la prestación de servicios.

A partir del decreto 18169/69 se autorizó la transferencia a provincias de hospedajes que habían sido expropiados en el año 1948: el Hotel Nacional de Turismo "Catamarca" y las Hosterías Nacionales de Turismo "Ancasti" y "Andalgalá", a la provincia de Catamarca; la Hostería Nacional de Turismo "Villa de
Soto", a la provincia de Córdoba; los Hoteles Nacionales de Turismo "Corrientes" y "Paso de los Libres", a la provincia de Corrientes; el Hotel Nacional de Turismo "La Rioja", a la provincia de La Rioja; y el Hotel Nacional de Turismo "San Luis", a la provincia de San Luis.

Esta retracción estatal se profundizó con una serie de concesiones otorgadas a los sindicatos, que se convierten progresivamente en los actores centrales del sistema de turismo social argentino. La Ley de Asociaciones Profesionales (LEY 14455/58) sancionada por Frondizi, que había reglamentado el accionar de las organizaciones gremiales exceptuando a éstas del pago de toda carga o gravamen impositivo, se complementó con la Ley de Obras Sociales (18610/70), que incrementó sus recursos económicos y determinó la adhesión obligatoria de servicios asistenciales y sociales. Estas medidas ocasionaron la propagación de hoteles, colonias y complejos sindicales en los principales destinos turísticos nacionales, especialmente en Córdoba y Mar del Plata, hasta mediados de 1970 (PASTORIZA, 2002).

Con el regreso del peronismo al gobierno, se volvió a jerarquizar el área, con la creación de la Subsecretaría de Turismo Social, dependiente de la Secretaria de Estado de Deportes y Turismo dentro del Ministerio de Bienestar Social (DECRETOS 339/73 y 1391/74). Entre sus variadas acciones, cabe destacar la promoción del turismo social con especial énfasis en los grupos carentes de cobertura social, el fomento de la construcción de hoteles y hosterías a partir de recursos propios y la realización de importantes obras de infraestructura en las Unidades Turísticas, incluyendo la construcción de un polideportivo en Embalse (1973), que permitió el relanzamiento de los torneos deportivos Evita.

Con el último golpe de Estado, el área volvió a descender a Dirección General, adscrita a la Subsecretaría de Deportes y Recreación de la Secretaría de Acción Social (decreto 2697/78), quedando relegada a dicho departamento con motivo a la realización del Campeonato Mundial de Fútbol (1978). El autodenominado "Proceso de Reorganización Nacional" derogó el Decreto 1391/74 en todo lo referente al área de turismo social y sus unidades dependientes; para, finalmente, cancelar el histórico Fondo de Turismo Social creado en los primeros gobiernos de Perón, que había logrado resistir distintas embestidas. A fines de los 1970, el entonces ministro de Economía, José Alfredo Martínez de Hoz, decidió englobar dicho fondo dentro del IVA, implicando una quebranto irremediable para el desarrollo del turismo social en el país.

La vuelta de la democracia significó la reincorporación definitiva del turismo social en la 
agenda gubernamental. Las recurrentes crisis económicas y la sustitución del Estado Benefactor por otro de corte Neoliberal, hicieron que ocupe un lugar secundario entre las políticas nacionales, lejano a la magnitud que alcanzó en los años 1950. Los gobiernos asumieron nuevas funciones en el área, proclamando al turismo como factor de crecimiento y de internacionalización, dentro de un proceso de retracción de la intervención del Estado, pérdida de derechos sociales y aumento de la iniciativa privada (Figura 3).

Figura 3. Reformulación del turismo social como asunto público (1983-2015).

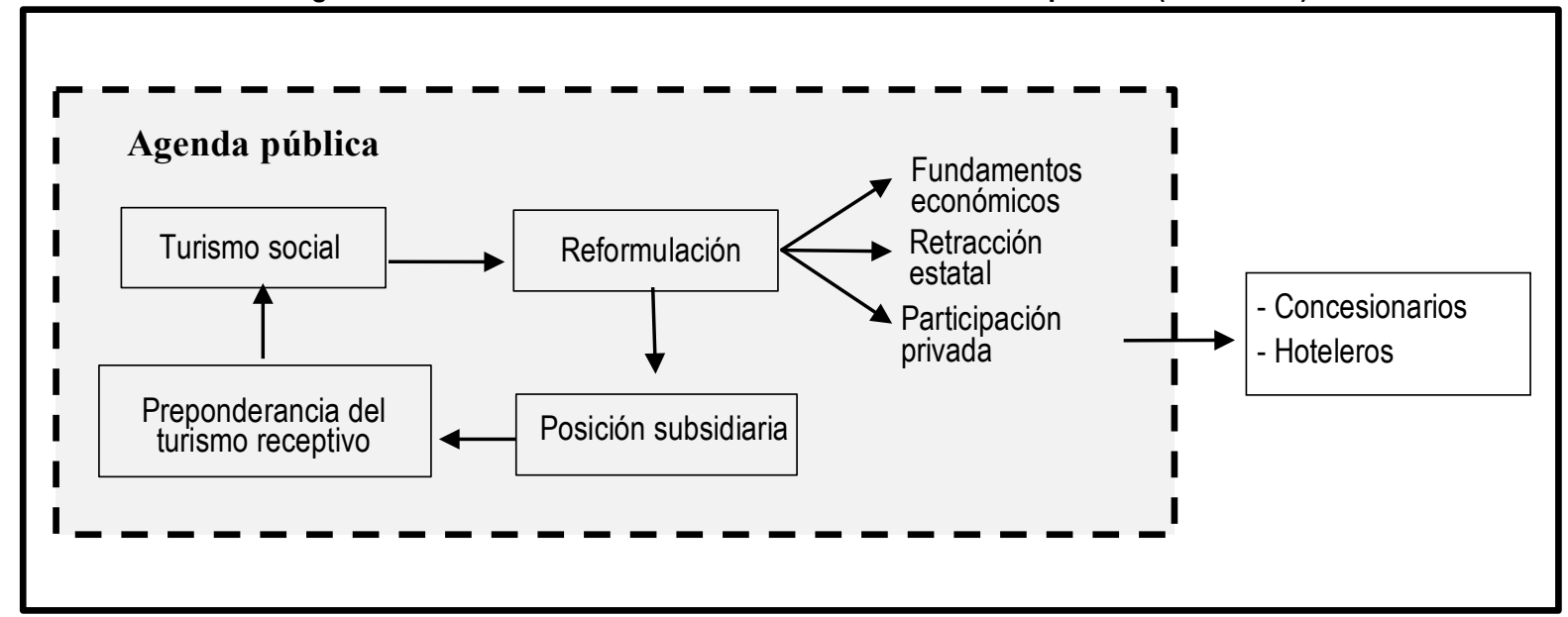

Fuente: Schenkel, 2017.

El turismo receptivo, se constituyó en una actividad clave, tendiente a atraer las necesarias divisas internacionales, ante la deficitaria balanza de pagos y la abultada deuda externa, para ocupar, a comienzos del siglo XXI, una posición preponderante entre las políticas del sector (Ley 25.997/05).

Desde entonces, se origina una reformulación de la política de turismo social, que amplió la participación a actores privados, concesionarios y hoteleros, planteó objetivos económicos asociados al crecimiento y la competitividad del sector e identificó nuevos destinatarios; que se consolida con la nueva Ley Nacional de Turismo, sancionada en el año 2005 (Figura 3). Los sucesivos gobiernos promueven programas turísticos de ayudas económicas a las personas, específicamente a los colectivos de escolares, tercera edad, personas con discapacidad y familias de escasos recursos y mayores cargas familiares, para que puedan acceder a las prácticas turísticas. Mediante la concesión de los únicos complejos estatales que persistieron el proceso de transferencia, la Secretaría de Turismo ofrece una semana de vacaciones en Embalse y Chapadmalal, incorporando la estadía y la alimentación con servicio de pensión completa, sin cargo o con tarifa reducida. La avanzada política de construcción de infraestructura de mediados de los XX, fue desalentada, relegando incluso el mantenimiento de los complejos turísticos.

El gobierno del Dr. Raúl Alfonsín jerarquizó el área, relanzando la Subsecretaría de Turismo Social, luego Subsecretaría de Turismo Básico y Social
(Decreto 663/87), dentro de la flamante Secretaría de Turismo (DECRETO 739/86). La misma se destinó al fomento de las prácticas turísticas en los complejos estatales, afín de facilitar el acceso de los sectores sociales excluidos (DECRETO 739/86). El organismo se encontraba facultado para: programar y ejecutar acciones específicas; administrar y conducir las colonias estatales y promover la construcción de otras en el interior; formular y ejecutar planes específicos para familias, jóvenes, tercera edad y grupos de menores recursos económicos; entender en la concesión y prestación de los servicios a los contingentes de beneficiarios; coordinar con otros organismos estatales y privados la utilización de las Unidades Turísticas, mediante la articulación con obras sociales, mutuales, cooperativas y sociedades de fomento; y realizar giras de estudio junto a las áreas de educación de los diferentes niveles de gobierno. El proceso hiperinflacionario que atravesó el país a finales de los 1980 coartó el desarrollo de estas iniciativas.

En la década del 1990, los subsidios destinados a estos programas fueron exceptuados de la emergencia financiera debido a que los mismos "cumplen una finalidad social importante para el desarrollo integral del ser humano" (decreto 1930/90). Dentro de las políticas de Reforma del Estado impulsadas en el gobierno del Dr. Carlos Menem, la Subsecretaría es remplazada por la Dirección de Turismo Social y Básico, pretendiendo fomentar el "turismo social, básico y alternativo" en sus distintas 
modalidades y ejecutar las acciones requeridas para la prestación de servicios en las Unidades Turísticas (DECRETO 1135/91). Los Juegos Panamericanos de 1995 constituyeron una oportunidad para efectuar reformas en el complejo de Chapadmalal, como la construcción del Polideportivo, que alojó a deportistas por 60.000 días-turista (JGM, 1996).

A partir del decreto 292/95 los programas de tercera edad se articularon con los servicios turísticos del Instituto Nacional de Servicios Sociales para Jubilados y Pensionados (PAMI), con la transferencia de las prestaciones del PAMI a la Secretaría de Turismo, financiadas con recursos del organismo previsional. La Dirección de Turismo Social y Básico fue reemplazada por la Dirección de Prestaciones Turísticas, organismo que gestiona los programas hasta nuestros días, tendiente a atender directamente o por convenios con otros organismos públicos 0 privados la participación turística de jubilados y pensionados, escolares y familias carenciadas (DECRETO 1407/96). A lo largo de los '90, las prestaciones crecieron de manera sostenida, hasta alcanzar en el año 1998 el máximo de la década: 1.157.423 días/turistas ejecutados (Dirección de Prestaciones Turísticas, 2014).

La coalición de partidos que llevó a la presidencia al Dr. Fernando de la Rúa en el año 1999, a partir del secretario de Turismo, el Ing. Hernán Lombardi, inició una serie de modificaciones sustanciales en el sistema de turismo social vigente, argumentando que la concentración de las prestaciones turísticas en las Unidades Turísticas desde 1950, originaba un servicio de "alto costo", "baja calidad" y "bajo impacto" sobre otros destinos nacionales, siendo imperioso impulsar una reconversión del área, proclamando, por primera vez, fundamentos económicos asociados al impulso del turismo social (CGN, 2001; JGM, 2000, 2001).

La nueva Administración lanzó el Programa Federal de Turismo Social (2000), surgido del Plan Nacional de Desarrollo Turístico Sustentable (20002003), con los objetivos de diversificar la oferta a partir de nuevos destinos, propiciar la generación de empleo, atenuar los problemas de estacionalidad, facilitar el aumento de actividad de las pymes y recibir propuestas y aportes de la actividad privada (RESOLUCIÓN 427). A diferencia del Programa Unidades Turísticas, promovió la cooperación con organizaciones empresariales de segundo grado, provincias, municipios y prestadores turísticos, a partir de contratos de adhesión formal. La propuesta ofrecía un paquete turístico con un subsidio de un $80 \%$ de la tarifa vigente, que incluía estadía de entre cinco a siete noches, servicio de pensión completa y una excursión. Los destinos del programa en un principio fueron Iguazú, Termas de Río Hondo, Esquel, Córdoba,
Miramar, Municipio Urbano de la Costa, Mendoza, Merlo, Gualeguaychú y Concepción del Uruguay.

Las Unidades Turísticas en tanto, pasaron a gestionarse a partir de un nuevo sistema de concesión de servicios, que, según proclamaba el Gobierno Nacional, permitía un ahorro de $\$ 10.000 .000$ (pesos diez millones) anuales. La Secretaría encomendó a las Universidades de Mar del Plata y Córdoba la formulación de los Máster Plan de las Unidades Turísticas de Chapadmalal y Embalse (2000), a fin de evaluar distintas posibilidades de uso y transferencia. En este marco, suscribió con la Consejería de Cultura, Comunicación Social y Turismo de la Xunta de Galicia de España una Carta de Intenciones en octubre del año 2000, a fin de implementar la creación y puesta en funcionamiento de una Escuela de Hospitalidad en Chapadmalal, como resultado de la visita del presidente de España (JGM, 2001).

Las modificaciones incluyeron la disminución de los días/turista ofrecidos: para el periodo 1998-2001 las prestaciones turísticas cayeron un $75 \%$, permaneciendo abierta la UTCH sólo cuatro meses al año. A partir de la decisión política de reemplazar progresivamente las prestaciones estatales por establecimientos privados, la distribución de la demanda se equiparó con el nuevo programa: en el año 2001, el Plan Federal concentró el $29 \%$ de las prestaciones ofrecidas, la Unidad Turística de Chapadmalal (UTCH) el 31\% y la Unidad Turística de Embalse (UTE) el 40\% (JGM, 2003, 2004). En este marco se elaboró la justificación arquitectónica y de factibilidad económica para crear una sociedad del Estado (2001), con vistas a efectuar las privatizaciones y/o concesión de los inmuebles de Embalse y Chapadmalal, los únicos complejos que permanecían en manos del Estado (JGM, 2002).

La eclosión de la crisis en diciembre del año 2001, dejó todos estos proyectos inconclusos. El gobierno interrumpió las prestaciones turísticas en ambos Programas, suspendió los acuerdos con prestadores privados y clausuró establecimientos hoteleros de las Unidades Turísticas, consolidando el proceso de deterioro del último cuarto de siglo. Como se mencionara anteriormente, la quita del Fondo Nacional de Turismo Social había iniciado un declive de los complejos, que concluyó en plena crisis del 2001, con la clausura de edificios conexos y hoteleros, permaneciendo operativos sólo cuatro de los siete hoteles de Embalse (hoteles números 1, 4, 6 y 7) y cinco de los nueve de Chapadmalal (números 1, 2, 4, $5,7)$.

Conseguida una nueva estabilidad macroeconómica, a partir del gobierno del Dr. Néstor Kirchner se consolida la reformulación del turismo social como política pública. Ante un Estado que se 
reposiciona como actor clave en la arena turística, la entonces Secretaría de Turismo, luego Ministerio (2010), formula una política pública específica, que complementa los históricos fundamentos sociales que dan origen a la cuestión, con otros económicos, a fin de reimpulsar las prestaciones turísticas inmersas en un profundo retroceso. Con objetivos y acciones concretas, que se desarrollan en las distintas versiones del Plan Federal Estratégico de Turismo Sustentable (SECTUR, 2005), la iniciativa presenta una vocación de intervención global en el área, que incluye la recuperación de las Unidades Turísticas y la incorporación de una extensa oferta privada en distintos destinos nacionales, a partir de la Dirección de Prestaciones Turísticas, que continúa a cargo de la política.

Con la sanción de la Nueva Ley Nacional de Turismo (LEY 25997/05) el turismo deja de ser institucionalizado como mera actividad de ocio y recreación (LEY 14574/58) para ser proclamado como "actividad socioeconómica, estratégica y esencial", siendo ésta "prioritaria dentro de las políticas de Estado" (LEY 25997, Art. 1, 3). El turismo receptivo pasa a distinguirse como una "actividad de exportación" no tradicional y el sector privado como una "aliado estratégico" para su desarrollo, impulsando herramientas económicas similares a las que se otorgan a la actividad industrial, entre las que se destaca la creación del Instituto Nacional de Promoción Turística (INPROTUR), destinado a desarrollar programas, planes y estrategias para la promoción de los arribos internacionales.

La nueva norma declara al turismo "un derecho social y económico de las personas dada su contribución al desarrollo integral en el aprovechamiento del tiempo libre y en la revalorización de la identidad cultural de las comunidades" (LEY N ${ }^{\circ}$ 25.997, Art. 2). Destina un título específico al turismo social (V), así como su Decreto Reglamentario (IV), definiéndolo como "aquellos instrumentos y medios que otorguen facilidades para que todos los sectores de la sociedad puedan acceder al ocio turístico en todas sus formas, en condiciones adecuadas de economía, seguridad y comodidad" (LEY N²5.997/05, Art. 38).

Marcando una continuidad con la política de turismo social del primer Peronismo, el gobierno sostiene que la reactivación de este tipo de iniciativas significan la actualización y puesta en práctica del "concepto primigenio de Turismo Social del justicialismo" como vehículo para lograr una mayor equidad, bienestar y crecimiento de la ciudadanía excluida: "estamos convencidos que abrevando en sus fuentes afianzaremos el turismo social en forma definitiva partiendo del ejercicio pleno de un derecho"
(SECTUR, 2003; MINTUR, 2010). En este punto se destaca la importancia de emprender instrumentos concretos, a fin de aprovechar la manifiesta voluntad política para llevarlos a cabo, "quizá como ningún otro momento de la Argentina en las últimas décadas" (SECTUR, 2003, 2004), marcando un antes y un después con los distintos gobiernos sucedidos desde el último golpe de Estado.

Las prestaciones se estructuran a partir del tradicional Programa en Unidades Turísticas, en base a los complejos estatales de Chapadmalal (Buenos Aires) y Embalse (Córdoba), y el Programa Federal de Turismo Social (2000), que había surgido en vísperas de la crisis tendiente a combatir la estacionalidad de los destinos maduros. La gestión de ambos Programas parte de Planes específicos que determinan prioridades de selección a partir de colectivos de destinatarios. Continuando con los tradicionales, se implementaron los Planes Escolar, Tercera Edad y Familiar (RESOLUCIÓN N²48/00); y posteriormente, se incorporan Eventos y Estudio e Investigación (RESOLUCIÓN N${ }^{\circ} 481 / 13$ ), que se venían ejecutando informalmente.

Estos grupos de destinatarios representan una línea de continuidad con la política implementada en las últimas décadas, cuando el turismo social dejó de asistir a los sectores obreros, para dirigirse a distintos colectivos, como familias numerosas, jóvenes, tercera edad, personas con discapacidad o grupos de escolares, terciarios y universitarios, dando cuenta a las estructuras sociales dinámicas y fragmentadas que priman en el periodo.

Para la gestión de estos Programas, la Dirección de Prestaciones ejecuta una cantidad creciente de recursos económicos (Figura 4). Luego de caer de manera sostenida en vísperas y finales de la crisis, la participación del gasto vuelve a crecer a partir del año 2003, para alcanzar en el año 2010 el $54 \%$ de los recursos ejecutados en el área de Turismo, aunque aún por debajo del máximo de la década pasada ( $80 \%$ en 1997). La disminución en la participación con respecto a los '90, se asocia a la complejización que atraviesa la estructura organizacional a medida que se consolidan las necesidades económicas del área. La evolución de los recursos refleja cómo la Dirección disminuye su participación a partir del año 2005, momento que se sanciona la Ley de Turismo 25.997 y se comienzan a implementar los nuevos lineamientos destinados a consolidar al turismo como actividad económica y al turismo receptivo como área clave; esta disminución se acentúa incluso con la creación del Ministerio de Turismo (2010), que reafirma las necesidades económicas asociadas al desarrollo de la actividad (véase Figura 2). 
Figura 4. Participación del crédito destinado al turismo social en función del área.

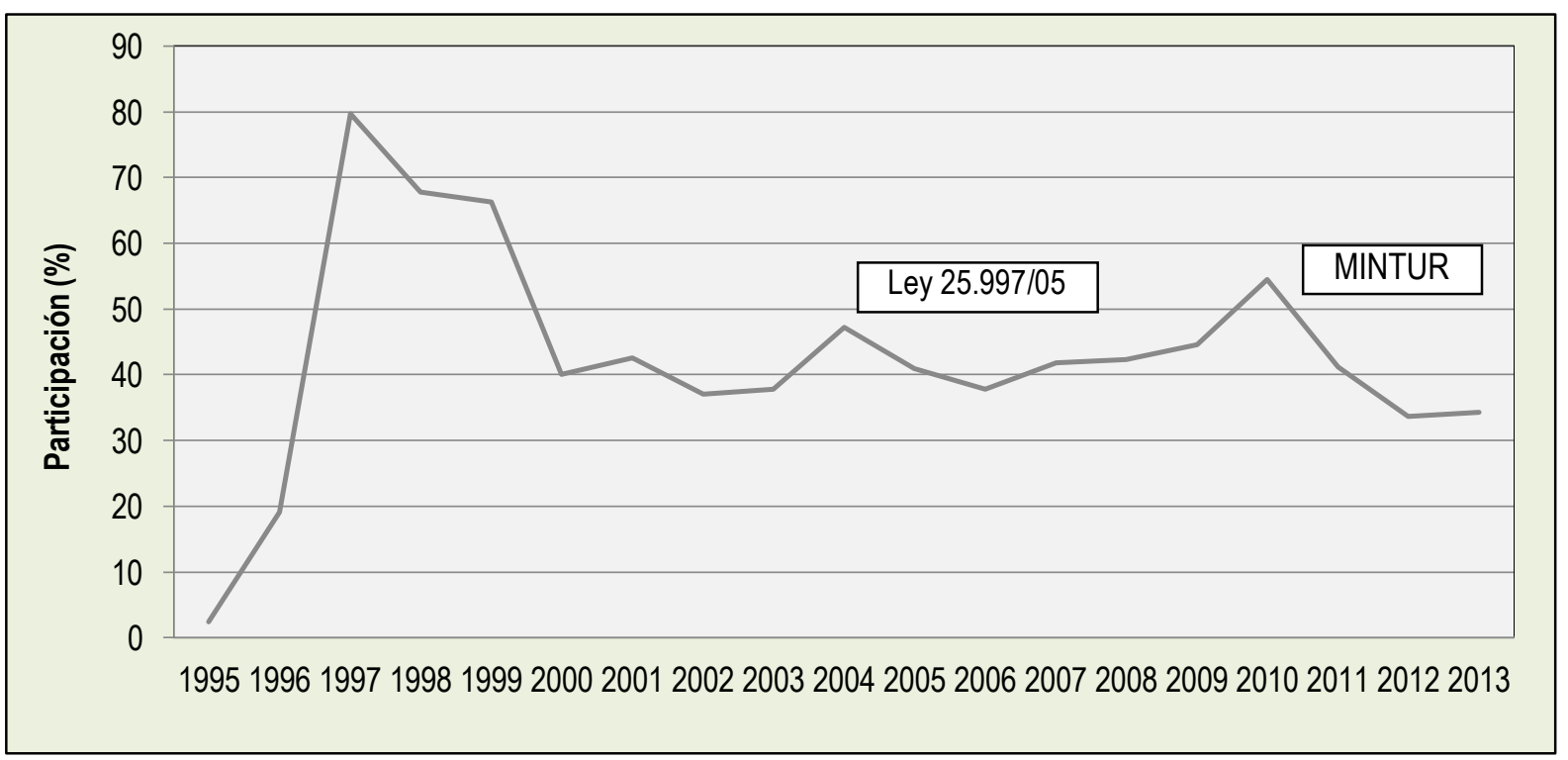

Fuente: Cuentas de Inversión (CGN, 1995-13).

A pesar de las prestaciones de turismo social, que luego de crecer post-crisis del 2001 se mantienen en los niveles de la década del ' 90 , en torno a los 150.000 beneficiarios anuales, se inicia un proceso de recuperación de los complejos, que logra incorporar cerca de 2.000 plazas al sistema estatal de turismo social (CGN, 1995-13). En la Unidad Turística de Embalse, con presupuesto de la propia Dirección, se recupera el antiguo pabellón de personal en desuso desde los años '80, fundando el Museo Eva Perón (2004), y se logra la reapertura del Polideportivo (2006) y del Hotel $n^{\circ} 3$ (2007).

La readecuación del Polideportivo, clausurado desde el último golpe militar, junto a la puesta en valor de las áreas deportivas, permitieron la reedición de los torneos Evita, luego de 31 años. A partir de la cláusula de inversión en infraestructura exigida a las empresas concesionarias, se recuperan las piletas del complejo, con sanitarios y confitería, y la Hostería (2008), cerradas desde 1990; y se adaptan parte de las instalaciones al colectivo de personas con problemas de movilidad, incorporando rampas de acceso, baños para discapacitados y ascensores en los Hoteles $n^{\circ} 4$ y 7 (2009). El Ministerio de Desarrollo Social constituye cinco cooperativas de trabajo (2010), a partir de las cuales se recupera el Hotel $n^{\circ} 2$ (2013), clausurado desde el año 2000 , y se inicia la recuperación del $n^{\circ} 5$, cerrado desde 1980.

En Chapadmalal, con recursos de la Dirección, se recupera el antiguo teatro del Hotel $\mathrm{N}^{\circ} 5$ que estaba en desuso, fundando el Museo Eva Perón (2003), se logra la reapertura de los Hoteles $n^{\circ} 8$ (2003) y 9 (2004), cerrados desde el año 2000 , y se inicia la recuperación del $n^{\circ} 6$ (2014), clausurado desde los años '90, se reparan el Polideportivo y parte de los playones deportivos (2006), relanzando distintos campeonatos deportivos, y se adecua parte de las instalaciones al colectivo de discapacitados (2009), colocando ascensores en los Hoteles $n^{\circ} 1$ y 2 , baños accesibles en el Hotel $n^{\circ} 5$, e instalando rampas de acceso en los Hoteles 1, 2, 4, 5, 7, 8 y 9. Por medio de la cláusula de inversión en obras, se logra habilitar el sector del paseo de los artesanos (2008), previo saneamiento del Lago, instalando un muro de contención y pérgolas, y se inaugura la Parrilla del Lago (2012).

A finales del año 2014 permanecen cerrados tres establecimientos: el Hotel $n^{\circ} 5$ en Embalse y los Hoteles 3 y 6 en Chapadmalal, este último en proceso de reparación desde el año 2014. El $n^{\circ} 5$ se encuentra clausurado desde 1980, la falta de custodia en el lugar favoreció un saqueo progresivo, que ha dejado el mismo en estado ruinoso. Con el objetivo de obtener fondos internacionales para su reconstrucción, la entonces SECTUR firmó un convenio con la Administración de Parques Nacionales (2004), a fin de ceder su uso por un plazo de 99 años para crear una Escuela de Guardaparques y Educación Ambiental; sin embargo, la transferencia nunca se concretó.

En cuanto a explotación de las Unidades, las mismas permanecen a cargo de empresas privadas que asumen la prestación de los servicios de comedores, bares, atención de habitaciones, limpieza general, mantenimiento de edificios e instalaciones y explotación de locales comerciales de los hoteles y servicios de apoyo. Las pautas de concesión representan una continuidad del proceso que se inició en la década del 1970. Las modificaciones responden a la incorporación de nuevos bienes inmuebles, a 
medida que se avanza en el periodo de recuperación de los complejos, y la actualización del precio de referencia del Día/Turista (Resoluciones de la SGPN $N^{\circ} 1011 / 04$ y 1012/2004; Resoluciones del MPN N ${ }^{\circ}$ 349/09 y 350/09; Resoluciones del MTN No 196/12 y 197/12).

\section{REFLEXIONES FINALES}

El análisis de la evolución del turismo social como asunto público permite identificar la importancia que adquiere esta política en la problematización de la cuestión turística, contemporánea a la institucionalización del área y al impulso de los instrumentos que sentaron las bases para el desarrollo del sistema turístico argentino.

A diferencia de lo que sucede con la cuestión turística en general, que adquiere una relevancia creciente desde su institucionalización, el turismo social presenta una importancia itinerante en el devenir histórico, asociada a las distintas funciones que asumieron los gobiernos en la materia, la inestabilidad del sistema político, las recurrentes crisis económicas $y$ las transformaciones en los patrones que condicionan la toma de decisiones (Figura 5).

Figura 5. Evolución del turismo social y de la política turística argentina

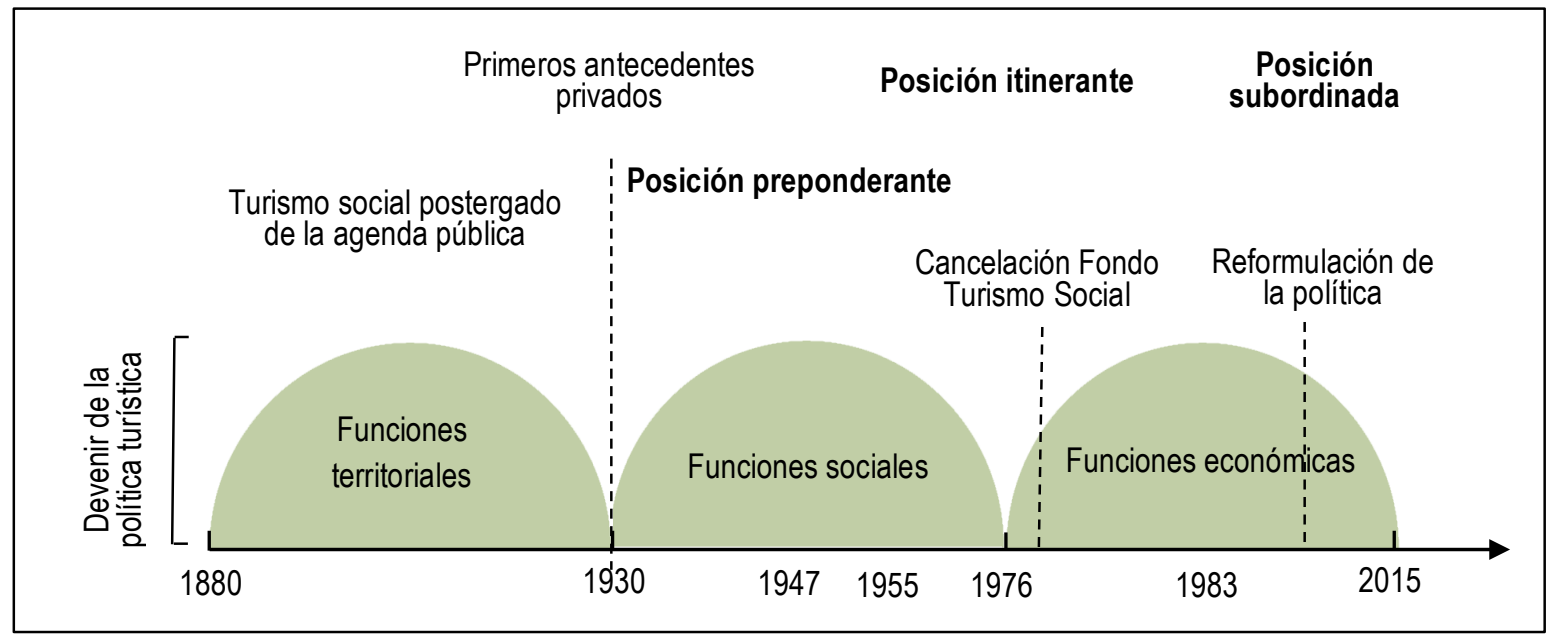

Fuente: Schenkel, 2017.

Mientras primaron las necesidades territoriales del turismo, la problemática del acceso a las prácticas turísticas se mantuvo postergada de la agenda gubernamental, sin articular un interés significativo en el sistema político que motivara el impulso de una política específica. Las acciones destinadas al turismo social se iniciaron principalmente en la década del treinta y como en materia turística en general, surgieron a partir de actores privados. Asociaciones cristianas y laicas, empresas ferroviarias y sindicatos, reprodujeron las primeras acciones que se estaban desarrollando en Europa. El Estado acompañó estas primeras iniciativas indirectamente y, en casos puntuales, contribuyó a su desarrollo con financiación específica.

A partir de las políticas sociales que surgieron al calor del Estado Benefactor, se comenzó a imponer progresivamente la función social del turismo como asunto de gobierno. La presencia política que adquirieron los colectivos obreros como sujetos de derechos, promovió el impulso del turismo social como política gubernamental, asociada al principio de justicia social. La cuestión alcanzó una posición preponderante en el área turística, que perduró incluso hasta el último cuarto de siglo. Las extensas distancias con los principales centros turísticos emisivos, el escaso desarrollo tecnológico en el ámbito de los transportes y las comunicaciones y el retrasado proceso de democratización de las prácticas turísticas de los países vecinos, dejaron al turismo receptivo en un segundo plano, hasta fines de la década de 1970.

El Primer Peronismo cristalizó el turismo social como medida distributiva, tendiente a disminuir la inequidad entre las diferentes posiciones del entramado social. El Estado se convirtió en el principal promotor y articulador de este tipo de iniciativas, que, como en pocos países en el mundo, incluyó la construcción de complejos turísticos propios. La política se regularizó y extendió al conjunto del territorio nacional, destinando por primera vez financiación específica. En esta política social del turismo, el movimiento obrero ocupó un lugar central, forzando mejoras laborales, articulando con los programas estatales $y$, en muchos casos, construyendo infraestructura turística propia para sus afiliados.

El periodo post-peronista circunscribe una posición itinerante del turismo social en la agenda 
gubernamental, asociada a la alta inestabilidad del sistema político. A partir de la invalidación de normas, la transferencia de recursos a provincias, sindicatos y privados, se desarticuló progresivamente el sistema estatal de turismo social, para nunca repetir el desarrollo alcanzado en los años 1950.

Los interregnos democráticos pretendieron jerarquizar la cuestión en la agenda gubernamental, a partir de las colonias de vacaciones que resistieron el vaciamiento, ocasionando escasos resultados a causa de la alta inestabilidad política. Paralelamente a esta retracción estatal, los sindicatos consolidaron su actuación en el área, convirtiéndose en actores centrales del sistema de turismo social argentino.

A partir del último golpe de Estado, la aplicación de recetas de ajuste estructural y liberalización económica, inició un proceso de precarización de los derechos sociales, que incluyeron aquellos ligados al ocio. La cancelación del histórico Fondo de Turismo Social a fines de los 1970, implicó un quebranto irremediable en el desarrollo del turismo social, representando el fin del periodo que había circunscripto el origen y la consolidación de la cuestión como política pública a mediados del siglo XX.

A pesar de que el restablecimiento del orden democrático significó la reincorporación del turismo social en la agenda gubernamental, la importancia creciente que adquiere el turismo receptivo, asociado a necesidades de internacionalización y crecimiento económico del Estado, hacen que ocupe una posición subsidiaria entre las políticas del sector, transfiriendo una cantidad creciente de los recursos del área, que afectó incluso el mantenimiento de los complejos turísticos. Los decisores públicos iniciaron una reconversión del turismo social como política pública, que amplió la participación a actores privados, concesionarios y hoteleros, planteó objetivos económicos asociados al crecimiento y la competitividad del sector e identificó nuevos destinatarios; que se consolida en el periodo de postcrisis del año 2001.

Ante un Estado Nacional que se reposicionó como actor clave en el área turística, la entonces Secretaría de Turismo, desarrolló una política pública específica, que complementó los históricos fundamentos sociales que dieron origen a la cuestión, con otros económicos, a fin de reimpulsar las prestaciones turísticas estatales inmersas en un profundo retroceso desde la crisis.

El nuevo gobierno promueve significativos avances en el área, destacándose: los avances normativos, a partir de la nueva Ley Nacional de Turismo, se proclamó un "derecho social y económico" de las personas y se sentaron las bases para el impulso de políticas de turismo social, tendientes a hacer efectivo el acceso a aquellos sectores que permanecen marginados de su disfrute; y avances de infraestructura, mediante un proceso de recuperación de los complejos estatales, se incorporaron plazas al sistema de turismo social luego de décadas de retracción.

Estos significativos avances, contrastan con el sistema de turismo social que se presenta prácticamente inalterable. A pesar de la retórica oficial, que afirma recuperar el turismo social del primer Peronismo luego de décadas de abandono, expresando una continuidad con lo llevado a cabo en los años 1950, y, al mismo tiempo, una ruptura con la política implementada en el último cuarto de siglo; la política de post-crisis, consolida el proceso de reformulación que se desarrolla desde el regreso de la democracia.

El órgano ejecutor creado a mediados de los 1990, incluso las autoridades a cargo del área; los programas y planes, estructurados en un sistema de subvenciones y acuerdos de precios, en servicios de estadía y alimentación, destinados a colectivos de tercera edad, familias, escolares y personas con discapacidad; la cantidad de personas beneficiadas, en torno a los 150.000 beneficiarios anuales; los actores relevantes que participan del sistema, centrado en concesionarios y hoteleros; los fundamentos que justifican la acción en el área, así como los recursos asignados; sin presentar cambios sustanciales, constituyen una extensión de la acción pública implementada en las últimas décadas.

Como las demás políticas turísticas, el turismo social se presenta como subsidiario al turismo receptivo, área prioritaria en la agenda gubernamental como "actividad de exportación no tradicional", que pasa a concentrar una cantidad creciente de los recursos afectados.

Finalmente, los aportes conceptuales y metodológicos que se desprenden de esta investigación, buscan contribuir a futuros estudios circunscriptos al análisis de políticas turísticas y del turismo social, particularmente en América Latina, desde sus especificidades teóricas y prácticas. El turismo social en Latinoamrica aún tiene el enorme desafío de responder a la problemática de la inequidad turística, reduciendo la distancia entre el discurso de inclusión asociado a los programas de turismo social y los escasos resultados que surgen de su desarrollo (SCHENKEL, 2017).

\section{REFERENCIAS}

BUREAU INTERNATIONAL DU TOURISME SOCIAL - BITS. (1972). Carta de Viena. Viena, Austria 
CAZES, George. Turismo social. En Jafari, Jafar, Enciclopedia de turismo (pp.659-660). Madrid: Editorial Síntesis, 2002.

CONTADURÍA GENERAL DE LA NACIÓN - MECON. Cuenta de inversión. Secretaría de Hacienda, 2001.

COMISIÓN EUROPEA. Dictamen del Comité Económico y Social Europeo sobre 'Turismo social en Europa'. C 318/67, Comisión Europea, 2006.

FRANCO, Rolando. Modelos de política social en América Latina en el último cuarto de siglo. Cap. V, pp. 147-168. En: FRANCO, Rolando; LANZARO, Jorge (Coords.). Política y políticas públicas en los procesos de reforma de América Latina. Buenos Aires: Miño y Dávila, 2006.

GONZÁLEZ TACHIQUÍN, Marcelo. El estudio de las políticas públicas: un acercamiento a la disciplina. Revista Quid Juris, 99-116, 2004.

HUGHES, Howard. Holidays and the economically disadvantaged. Tourism Management, 193-196, 1991.

JEFATURA DE GABINETE DE MINISTROS - JGM. Memoria detallada del estado de la Nación del año 1995. JGM, 1996.

JEFATURA DE GABINETE DE MINISTROS - JGM. Memoria detallada del estado de la Nación del año 1999. JGM, 2000.

JEFATURA DE GABINETE DE MINISTROS - JGM. Memoria detallada del estado de la Nación del año 2000. JGM, 2001.

JEFATURA DE GABINETE DE MINISTROS - JGM. Memoria detallada del estado de la Nación del año 2001. JGM, 2002.

KINDERIS, Remigijus. Adaptation of Social Tourism as of Alternative form of Tourism in Eurupe. GeoJournal of Tourism and Geosites, 1 (5), 7-15, 2010.

LOPES DOS SANTOS, Aristides Faria. Administração pública do turismo: experiências sulamericanas de turismo social em perspectiva comparada (Argentina, Brasil e Chile). Anais Bras. de Est. Tur. ABET, 6 (3), 56-66, 2016.

LOSADA TRABADA, Antonio. Entre la ciencia política básica y la ciencia política aplicada; de la política a las políticas, del análisis a la gestión. Revista de Investigaciones Políticas y Sociológicas, 2 (2), 63-81, 2003.

LOWI, Theodore. American Business and Public Policy, Case Studies and Political Theory. World Politics, 16 (4), 677715, 1964.

LOWI, Theodore. Four Systems of Policy, Politics and Choice. Public Administration Review, 32 (4), 298-310, 1972.

MINISTERIO DE TURISMO DE LA NACIÓN. Encuesta de Viajes y Turismo en Hogares (EVyTH). Buenos Aires: Subsecretaría de Desarrollo Turístico, Mintur, 2010.

MUNÍZ AGUILAR, Daniel. La política de turismo social. Sevilla: Consejería de Turismo y Deporte, Dirección General de Planificación Turística, 2001.
PASTORIZA, Elisa; TORRE, Juan Carlos. Mar del Plata, un sueño de los argentinos. En: DEVOTO, Fernando; MADERO, Marta (Dirs.), Historia de la vida privada en la Argentina. La Argentina entre multitudes y soledades. De los años treinta a la actualidad (pp. 48-77). Buenos Aires: Taurus, 1999.

PASTORIZA, Elisa (Ed.). Las puertas al mar. consumo, ocio y política en Mar del Plata, Montevideo y Viña del Mar. Buenos Aires: Biblos, 2002.

PÉREZ SÁNCHEZ, Margarita. El Estudio de las Políticas Públicas (pp. 51-75). En: PÉREZ SÁNCHEZ, Margarita (Ed.), Análisis de Políticas Públicas. Granada: Universidad de Granada, 2006.

PERÓN, Juan Domingo. Discurso en una reunión de dirigentes gremiales, sobre la política social del gobierno. Prensa Oficial de la República, Buenos Aires, 9 de Abril de 1945.

Presidencia de la Nación. $2^{\circ}$ Plan Quinquenal. Subsecretaría de Informaciones, Prensa Oficial de la República, Buenos Aires, 1953.

SCARZANELLA, Eugenia. El ocio peronista: vacaciones y 'turismo popular' en Argentina (1943-1955). Entrepasados. Revista de Historia, 7 (14), 65-84, 1998.

SCHENKEL, Erica. La inserción del turismo social a la agenda pública en la Argentina. Papers de Turisme, 2015.

SCHENKEL, Erica. Política turística y turismo social. Una perspectiva latinoamericana. Editorial CICCUS CLACSO, 2017.

SECRETARÍA DE TURISMO DE LA NACIÓN - SECTUR. Turismo 2016. Plan Federal Estratégico de Turismo Sustentable. SECTUR, 2005.

SECRETARÍA DE TURISMO DE LA NACIÓN. Turismo Social en la Argentina. Turismo para todos. Sectur, Buenos Aires, 2003.

SECRETARÍA DE TURISMO DE LA NACIÓN. Primer aniversario del Museo "Eva Perón" de la Unidad Turística de Chapdmalal. Sectur prensa, 16 de enero de 2004.

SUBIRATS, Joan. Políticas públicas e inclusión social. Factores territoriales y gobiernos locales. Instituto de Gobierno y Políticas Públicas, 1-29, 2010.

SUREL, Ives. Relaciones entre la política y las políticas públicas. (pp.43-73). En: FRANCO, Rolando; LANZARO, Jorge (Coords.), Política y políticas públicas en los procesos de reforma de América Latina. Buenos Aires: Miño y Dávila, 2006.

VALENCIA, Germán; ÁLVAREZ, Yohan. La ciencia política y las políticas públicas: notas para una reconstrucción histórica de su relación. Estudios Políticos, 33, 93-121, 2008.

VILELA DE ALMEIDA, Marcelo. The development of social tourism in Brazil. Current Issues in Tourism, 14 (5), 483-489, 2011.

Processo Editorial / Editorial Process

Editor Chefe/Editor-in-chief: PhD Thiago D. Pimentel (UFJF).

Recebido em 07 de Julho de 2017; aceito em 26 de Setembro de 2017; publicado online 31 de Outubro de 2017.

Received on July 07, 2017; accepted on September 26, 2017, published online on October 31, 2017.

Artigo original / Original article. Revisão cega por pares / Double bind review. 